\title{
Improving postgraduate nursing research output: A South African nursing science perspective
}

\author{
P C Chukwuere, MSc; L A Sehularo, PhD; M E Manyedi, PhD; M M Ojong-Alasia, MSc \\ School of Nursing Science, Faculty of Health Sciences, North-West University, Potchefstroom, South Africa
}

Corresponding author: P C Chukwuere (chibuikeprecious45@yahoo.com)

Background. Postgraduate nursing research programmes prepare professional nurses for receiving Master's or doctoral degrees, foster growth of the profession and strengthen the nation's health sectors through development and implementation of innovative approaches for better nursing care. Enrolment in and completion of postgraduate nursing research programmes follow rigorous processes, involving the student, supervisor(s) and university. Objectives. To review the relevant literature obtained from a computerised database search that focused on improving postgraduate nursing research throughput in South Africa (SA) to synthesise ideas and draw conclusions regarding the topic being discussed.

Methods. An unsystematic, narrative literature review approach was adopted for a computerised database search.

Results. The study revealed that postgraduate nursing research throughput could be improved through enrolment of a greater number of Master's and doctoral students across SA universities, and adequate provision of structures for accessing information, e.g. the latest technologies. The study also revealed the need for adequate support of supervisors with the necessary resources and continuous training of more supervisors in innovative methods for appropriate development of the requisite skills to strengthen research supervision.

Conclusion. There is a dire need to promote postgraduate nursing researchers owing to the importance of professional growth, development of new knowledge and university funding.

Afr J Health Professions Educ 2020;12(3):114-118. https://doi.org/10.7196/AJHPE.2020.v12i3.1337

Nursing research exposes professional nurses to a wealth of knowledge and experience, which could entail using the emerging experiences to understand how to interact appropriately in the new world, expand one's horizon of thinking and one's approach to problem-solving. ${ }^{[1]}$ Nursing research explores the preparedness of professional nurses to leadership positions, further education, appropriate measures to improve teaching and learning and professional growth. ${ }^{[2,3]}$ Nursing research programmes produce experts on whom South African (SA) healthcare institutions are dependent for the promotion of quality healthcare services, and expansion of preventive strategies and healthcare policies. ${ }^{[4]}$ Furthermore, nursing research strengthens evidence-based healthcare practices for the effective functioning of healthcare institutions. ${ }^{[5]}$ It also leads to increased career opportunities for professional nurses and to Master's and doctoral degrees in a chosen research area. ${ }^{[6]}$

Conducting nursing research demands organisation, diligence, following systematic patterns of enquiry, looking for answers, validating existing research knowledge and generating new evidence-based knowledge. ${ }^{[7,8]}$ In $\mathrm{SA}$, there is a dire need for more throughput of postgraduate research graduates. Nursing is not an exception, owing to the low level of completion among those who enrol for the programme. ${ }^{[9]}$ The researchers in this study conducted an unsystematic narrative literature review from computerised databases, synthesising their findings to foster an understanding of how to improve postgraduate nursing research throughput in SA.

\section{Objectives}

The purpose of this unsystematic narrative literature review was to explore the relevant literature obtained from a computerised database that focused on improving postgraduate nursing research throughput in SA to synthesise ideas and draw conclusions.

\section{Methods}

An unsystematic narrative literature review, also known as a narrative review, was done in this study, ${ }^{[10]}$ and is distinct in its approach, as it enables periodic synthesis of the existing literature and drawing of conclusions. ${ }^{[11,12]}$ Adopting an unsystematic narrative literature review enabled the researchers to review the relevant literature from a computerised database search and to synthesise findings to foster measures for improving postgraduate research throughput in nursing science in SA. A literature search was conducted in three databases, i.e. Google Scholar, ScienceDirect and Sabinet Online, with regard to articles not beyond 2009, using the following keywords: 'improving,' 'nursing research', 'output' and 'postgraduate research. Owing to paucity of the literature in this regard, the researchers carefully reviewed and synthesised the findings of the available literature, thereby drawing possible solutions and conclusions for the study.

\section{Brief overview of postgraduate nursing research}

Nurses with Master's and doctoral degrees are leaders in healthcare and education globally. Graduates with these qualifications are necessary for managerial and other leadership positions in healthcare/research and higher education institutions. ${ }^{[13]}$ Postgraduate research in nursing prepares nurses for delivering cost-effective healthcare services and evidence-based nursing care, enhancing critical thinking and improved solving of healthcare problems. ${ }^{[14]}$ Those with Master's and doctoral degrees contribute to improving human resource shortages in the health professions. ${ }^{[15]}$ Excellent 
Master's or doctoral research contributes to the academic or professional field and most importantly fulfils the requirement for awarding a degree. ${ }^{[16,17]}$ Exposing student nurses to a good research background during undergraduate projects enhances their understanding of research and could benefit them during postgraduate research programmes. However, in most cases, schools find it difficult to expose their students to this information because of factors such as poor programme management, excessive student workload and poor time management, which translate into lack of adequate background knowledge of research. Most professional nurses who also enrol for postgraduate research programmes struggle to balance work and academia. Maintaining a balance between work and study, coupled with indifferences in perceptions regarding the need for postgraduate nursing research programmes, could lead to difficulties with enrolment and completion of a Master's or Doctorate in nursing science. ${ }^{[6]}$ Furthermore, multiple nursing roles and the brain drain are also among the factors discouraging professional nurses from enrolling and completing postgraduate research programmes. ${ }^{[14-18]}$ Most of those enrolling for postgraduate research programmes are faced with numerous difficulties and commitments, which affect their productivity in the programme. ${ }^{[19]}$

\section{Postgraduate nursing research in South Africa}

Completion of postgraduate research remains a vital concern for institutions of higher education in SA and worldwide. ${ }^{[18-20]}$ In SA, there has been an insufficient number of Master's and doctoral graduates across disciplines, including nursing science. ${ }^{[21,22]}$ SA has a $<20 \%$ throughput rate of doctoral nursing graduates per year, which poses a challenge to postgraduate nursing research. ${ }^{[23]}$ Therefore, the high postgraduate dropout negatively affects universities' economic resources and deprives them of Master's and doctoral graduates for the growing labour market, especially in the nursing profession. ${ }^{[24,25]}$ This dropout rate affects all disciplines in SA, which is detrimental to economic growth. Universities are key drivers of innovation and change through research efforts of Master's and doctoral students. ${ }^{[9]}$

From 2000 to 2006, at the College of Health Sciences, University of KwaZulu-Natal, Durban, SA, Master's and doctoral nursing programmes had a completion rate of $11 \%$ and $10 \%$, respectively, with an average dropout rate of $56 \%$, especially for Master's programmes. ${ }^{[26]}$ The low throughput rate of postgraduate research students at SA universities is problematic, ${ }^{[9]}$ as there is a discrepancy between the high number of enrolments in postgraduate programmes, including nursing, and the completion rate. Therefore, the increase in students dropping out from their respective postgraduate nursing research programmes leads to discouragement among supervisors, low academic growth for supervisors and professional growth for nurses, while remuneration and university prestige are jeopardised.

Nurses constitute a vital part of the SA workforce, which necessitates completion of Master's and doctoral degrees to assist in placing the profession at a highly ranked professional position globally and to enhance the delivery of quality healthcare services for all users of such care. However, enrolling for and completing a postgraduate research programme in nursing are challenging for the school management, supervisors and students. Many prospective postgraduate research students across all disciplines perceive research as insurmountable, which also applies to nurses. An adequate understanding of the underlying principles and their application leads to an easier ride. ${ }^{[27]}$ Hence, the need for understanding the principles and starting correctly is imperative. Research is a complex term used to denote any type of investigation geared towards finding a solution(s) to an existing problem and generating new knowledge through rigorous processes. ${ }^{[28]}$ Postgraduate research programmes are crucial to investigate new phenomena that lead to discoveries, knowledge creation and possibly solutions and strategies across the socioeconomic and political landscape..$^{[9]}$ Such programmes in all disciplines contribute greatly to the development of a nation and institutions of higher learning. ${ }^{[29]}$

\section{Universities as key drivers in postgraduate nursing research programmes}

Universities are key role players in knowledge development and dissemination through utilisation of the collaborative functions of students and their supervisors - thus equipping students for the future. ${ }^{[26]}$ Globally, there is a high demand across universities for more postgraduate students - also in SA - especially with regard to nursing science. ${ }^{[27]}$ Postgraduate research programmes have proven to be an important source of income to universities through publications (during the course of the study and on completion of the research project) and also helps in marketing of their brand globally ${ }^{[30]}$ Postgraduate research constitutes a huge source of funds to university management, ${ }^{[2,6]}$ and universities also develop competent researchers, enabling the expansion of skills. Hence, the slow completion of postgraduate research programmes (Master's and Doctorates) across all disciplines, with nursing not being an exception, is a serious concern to universities. ${ }^{[31]}$ They suffer with regard to subsidies when a student fails to complete a postgraduate research programme in the appropriate time; therefore, throughput rates are important to higher institutions of learning. ${ }^{[32]}$

Universities face challenges regarding student demands and changes in government policies. ${ }^{[33]}$ Studies have shown that SA has a shortage of competent supervisors, especially in health science faculties, including nursing science. Recently, there has been an increase in the intake of postgraduate students in universities across SA, but the limited number of competent supervisors increases the workload, thereby undermining their productivity and generally leading to a low output of Master's and doctoral graduates. ${ }^{[34]}$ The slow rate of completion of postgraduate research programmes by nurses deprives the universities of the various financial subsidies. ${ }^{[23]}$

\section{Supervisors as important role players in postgraduate nursing research}

Postgraduate supervision is an interactive process, contributing to quality dissertations and theses. ${ }^{[32]}$ Such supervision is also important in fostering improvement in the quality of care and for successful completion of Master's and doctoral programmes. ${ }^{[35]}$ Supervisors play a pivotal role in influencing the academic progress of postgraduate research nursing students. They use the combination of projection technique and personality profile to enable students to understand what is necessary to enhance their chances of completing their studies. ${ }^{[32]}$ Standard postgraduate research supervision is a vital requirement for successful completion of a postgraduate programme. ${ }^{[36]}$ Undertaking postgraduate research supervision is an enormous, but rewarding challenge. Such supervision is performed in the university setting, with the university shouldering the overall support and development of the supervisor for adequate output. ${ }^{[38]}$

Postgraduate nursing research supervision is important for producing quality researchers. ${ }^{[35]}$ Through postgraduate supervision roles, nursing supervisors manage and guide the research progress of their supervisees 
at different levels of study. Supervisors are rewarded for contributing to the graduation of students by either being promoted in their various positions, general institutional obligations, self-actualisation, expansion of research horizons and professorship awards. Hence, postgraduate nursing research supervision is considered a crucial aspect of facilitating postgraduate graduation. Such supervision poses a huge challenge to supervisors because of the heavy workload or lack of adequate experience, which directly affects the throughput of students. Many postgraduate nursing research supervisors lack the quality time to allow them to participate in training programmes for mentorship, which will contribute to their development. ${ }^{[23]}$ To that effect, advancement in scholarly development among nursing research supervisors is undermined owing to lack of time. Interestingly, in SA, only five academic nurses have reached the National Research Foundation rating. ${ }^{[37]}$ Furthermore, the slow rate of throughput of postgraduate students could be as a result of the inexperience of supervisors. Because of lack of competent supervisors, inexperienced ones have to supervise student researchers without proper mentorship, which directly reflects on the disappointing results. ${ }^{[23]}$

\section{Discussion}

Starting and completing a Master's or doctoral programme in nursing is a tricky journey, underpinned by taking the right steps at the right time. The preparedness of a prospective postgraduate nursing research student is a vital determining factor towards enrolment and completion of the degree programme. ${ }^{[38]}$ A nurse who appreciates the need for undertaking Master's or doctoral studies should take appropriate steps towards becoming acquainted with the embedded processes and challenges that follow. Therefore, combining daily practice with a Master's or doctoral programme is never an easy journey. Envisaging the end at the beginning strengthens the mind towards the challenges ahead and, importantly, towards adhering to the step-by-step processes involved. ${ }^{[39]}$ Therefore, the researchers in this study are of the view that a determined and focused individual always completes an undertaking. It is imperative to understand that as a postgraduate nursing student, especially at doctoral level, you are almost alone on the research journey, and you need to take the correct decisions throughout. Importantly, the writing of postgraduate nursing research can be challenging and time consuming, which demands skills for intellectual conceptual abilities and constructive thinking. Research across all disciplines follows structured, systematic, replicable and universally accepted formats that are purposely designed for solving of ambiguous problems within a specific area. ${ }^{[9]}$

Postgraduate research nursing students should have a personal target, decide on the direction they want to go and discuss it with their supervisor to attain a distinct consensus to work effectively. Such students should endeavour to understand that finalising and passing a good dissertation or thesis entail engaging with their supervisor and completing fundamental tasks, including:

- deciding on the field of research (conceptualisation of research ideas)

- choosing a topic

- choosing a supervisor

- discussing the research area or interest

- starting with writing (drafting a preliminary proposal).

A nurse who embarks on postgraduate research studies at a university should try to make clear-cut decisions on the area of research, consider the financial implications and job and family commitments, which may directly or indirectly affect their studies. ${ }^{[40]}$ However, the student can try to make contact with the school for a supervisor who shares their research interests. Supervisors, who are generally more knowledgeable in specific research areas, are expected to guide the student in decision-making. The research supervision processes should lead to knowledge creation and expertise in a chosen field of research. ${ }^{[26]}$ Therefore, it is essential for a prospective nurse researcher to consider an area of interest, conceptualise a research idea and discuss it with the supervisor.

The choice of research area of interest, identifying and constructing research topics, developing clear research questions, producing a good proposal and conducting the study are challenging to students. ${ }^{[4]}$ Master's or doctoral research processes can be rigorous, frustrating, depressive, monotonous or even daunting, but selecting an area of interest could help in navigating research-associated difficulties. Furthermore, a well-written research proposal enables easy navigation through the research ethical review committee, approval, conducting of the study and subsequent writing of the research findings. ${ }^{[41]}$

The choice of a supervisor can be challenging. At some universities, the management helps in assigning supervisors to Master's students, while the student has the choice of accepting to work with the assigned supervisor or make their own choice. However, this is more challenging to doctoral students, as they have the responsibility of contacting the university and selecting a supervisor(s) for their research. To that effect, the appropriate choice of a supervisor enhances the professional relationship between the student and the supervisor. For instance, when the supervisor has the same area of interest as the student, it leads to mutual understanding and professionalism. Students are expected to communicate well with their supervisors to foster appropriate working conditions. Communication is a vital component of nursing research supervision; hence, the student should prioritise communicating with their supervisor for timely completion of the study. ${ }^{[6]}$

Interestingly, the chosen topic for nursing research represents the umbrella for the entire study. The topic/title should be concise, comprehensive and contain few words. ${ }^{[22,43]}$ Research topics should demonstrate professional importance, be original, researchable, feasible and of interest to the nurse researcher ${ }^{[6]}$ The topic should be presented to the prospective supervisor for validation, and there should be consensus regarding the topic. This will enable the student and the prospective supervisor to start on the same page and to work together well. Preliminary research to obtain information on the chosen topic enables the researcher or student to conceptualise valid research ideas. Preliminary research also enables the student to determine if there is enough supporting literature, or an excess of literature, which might indicate that the topic is over researched. The preliminary research might also guide a nurse in selecting a topic without a preconceptualised research topic.

\section{Possible solutions}

Considering the individual and societal benefits of Master's and doctoral degrees in the SA nursing profession, it is imperative to acknowledge the possible solutions for improvement. SA postgraduate nursing research throughput could be improved by enhancing the method of enrolment, and more support for addressing students' personal and academic-related ordeals to promote completion and graduation rate. ${ }^{[13]}$ Postgraduate nursing research students need emotional support from their supervisors, which 
helps to encourage them regarding effective output. ${ }^{[32]}$ Adequate provision of structures for accessing information, such as the latest technology and library facilities, enables postgraduate nursing research students to obtain educational material for their studies. ${ }^{[33]}$

Supervisors have an important role in developing appropriate research capacity and competence among students. Hence, they should be properly supported with the appropriate resources and information for more research throughput. ${ }^{[34]}$ Furthermore, SA institutions should endeavour to encourage postgraduate research students to align their research with the current economic, educational, health and social challenges and adequate decisionmaking. ${ }^{[34]}$ Monitoring and reporting of student progress to the appropriate authority are imperative for timely completion of the study.

Consequently, the research environment and available support systems are integral components for completing postgraduate nursing research programmes. These environments primarily refer to the study context, which facilitates adequate data collection. Universities should prioritise the studies of their students and assist them where necessary. ${ }^{[27]}$ Postgraduate nursing research programmes are vital to society; therefore, students need to be adequately supported by institutional authorities, taking cognisance of the areas of the curriculum to enhance their success in their various roles after graduation. These might include teachers, research consultants, managers, mentorship and research scholarship. ${ }^{[4]}$ Those with Master's and doctoral degrees are considered to have more advanced knowledge, and supervisors are therefore expected to have a high level of expertise in their respective fields. Owing to the increase in demands and intake of postgraduate nursing research students in the various higher institutions in SA and the limited number of supervisors, there is a need for continuous training of more supervisors and innovative methods for appropriate development of adequate skills, which will promote research supervision. ${ }^{[45]}$

Furthermore, improving postgraduate nursing research supervision should be contractual and evenly distributed among students, supervisors and the university; each role players can thus prioritise their various roles for timely completion of the study. ${ }^{[35]}$ Supervisors should understand their central roles in the completion of a postgraduate degree, taking cognisance of the complex nature of mentoring a student. ${ }^{[40]}$ Hence, relational orientation leadership is vital for postgraduate nursing supervision, as it encourages supporting, developing, supervising, recognising and empowering students. ${ }^{[35]}$ It is a complex process that requires competency, multiple skills and knowledge. Supervisors should continually improve their skills to enhance their abilities in guiding the students properly. Furthermore, postgraduate nursing research supervisors require a good knowledge of methodology, and facilitation and management skills for adequate research output. ${ }^{[26]}$ Exposing postgraduate nursing research students to research training, computer skills acquisition, information searches and stress management will help to improve throughput. ${ }^{[19]}$

\section{Conclusions}

Postgraduate nursing programmes help to prepare nurses for the provision of evidence-based practices and to advance the nursing profession through research. SA has a low throughput of postgraduate nursing graduates, specifically of Master's and doctoral degrees, as a result of numerous factors, as portrayed in the study. Hence, there is a dire need for adequate throughput of postgraduate nursing graduates, specifically at Master's and doctoral level.
To explore the topic of discussion, the study adopted an unsystematic, narrative literature review method, which enabled the researchers to cover distinct subheadings, including a brief overview of postgraduate nursing research in SA, universities as key drivers of postgraduate nursing research programmes, supervisors as important role players, as well as a discussion and conclusion. The literature was reviewed and synthesised in line with the topic of discussion. Findings revealed that postgraduate nursing research throughput could be improved through provision of more support for postgraduate nursing research students to enable them to address personal and school-related challenges. There should be provision of adequate structures, such as library facilities, encouragement of students to be innovative in their research areas and continuous training of supervisors to enable them to be grounded in their respective research areas.

\section{Recommendations}

- This study strongly recommends the supervision of postgraduate nursing research students by more than one supervisor. This will encourage expertise and prevent disruption should the supervisor be dismissed, incapacitated or pass away.

- Nurse researchers should be ethically sound; hence, faculty management or ethical bodies should endeavour to find common ground in maintaining ethical standards to minimise unnecessary delays.

\section{Declaration. None.}

Acknowledgements. The authors would love to acknowledge almighty God for His grace to complete this study.

Author contributions. All authors contributed equally to the manuscript.

Funding. None.

Conflicts of interest. None.

Burns N, Grove SK. Understanding Nursing Research: Building an Evidence-based Practice. 5th ed. Philadelphi Saunders, 2011

2. Mutula SM. Challenges of postgraduate research: Case of developing countries. S Afr J Lib Information Se 2011;77(2):184-190. https://doi.org/10.7553/77-2-60

3. Moule P, Goodman M. Nursing Research: An Introduction. 1st ed. Thousand Oaks, CA: SAGE, 2009

4. National Department of Health. The National Strategic Plan for Nurse Education. Training Practice. 2012/13 2016/17. Pretoria: NDoH, 2013.

5. Sheehan A, Comiskey C, Williamson C, Mgutshini T. Evaluation of the implementation of a PhD capacitybuilding program for nurses in South Africa. Nursing Res 2015;64(1):13-23. https://doi.org/10.1097 nnr.0000000000000069

6. Cleary M, Hunt GE, Jackson D. Demystifying PhDs: A review of doctorate programs designed to fulfil the need of the next generation of nursing professional. Contemp Nurse 2011;39(2):73-280. https://doi.org/10.5172/ conu.2011.273

7. Grove SK, Gray JR. Understanding Nursing Research: Building an Evidence-Based Practice. 7th ed. St Louis: Elsevier Health Sciences, 2018

8. Fain JA. Reading, understanding and applying nursing research. 5th ed. Philadelphia: FA Davis, 2017.

9. King C. A systematic review of challenges in research supervision at South African universities. 2018. https:/ King C. A systematic review of challenges in research supervision at So
www.preprints.org/manuscript $/ 201812.0305 / \mathrm{vl}$ (accessed 30 July 2020).

www.preprints.org/manuscript/201812.0305/v1 (accessed 30 July 2020). . Noble H, Smith J. Reviewing the literature: Choosing a review design. Evidence-based Nursing 2018;21(2):39-41 https://doi.org/10.1136/eb-2018-102895

1. Byrne JA. Improving the peer review of narrative literature reviews. Res Integrity Peer Rev 2016;1(1):1-12. https:// doi.org/10.1186/s41073-016-0019-2

12. Ferrari R. Writing narrative style literature reviews. Med Writing 2015;24(4):230-235. https://doi.org/10.1179/2 047480615Z.000000000329

13. Havenga Y, Sengane M. Challenges experienced by postgraduate nursing students at a South African university. Health SA Gesondheid 2018;23:1-9. https://doi.org/10.4102\%2Fhsag.v23i0.1107

14. Ojewale LY, Oluwatosin OA. Postgraduate education in nursing: Challenges and implications for nursing practice in Nigeria. West Afr J Nurs 2017;28(1):48-55.

15. Edwards N, Webber J, Mill J, Kahwa E, Roelofs S. Building capacity for nurse-led research. Int Nurs Rev 2009;56(1):88-94. https://doi.org/10.1111//j.1466-7657.2008.00683.x

16. Carter AG, Creedy DK, Sidebotham M. Efficacy of teaching methods used to develop critical thinking in nursing and midwifery undergraduate students: A systematic review of the literature. Nurse Educ Today 2016;40:209-218. and midwifery undergraduate students: A sy

17. Zimbardi K, Myatt P. Embedding undergraduate research experiences within the curriculum: A crossdisciplinary study of the key characteristics guiding implementation. Stud High Educ 2014;39(2):233-250 https://doi.org/10.1080/03075079.2011.651448

18. Essa I. Reflecting on some of the challenges facing postgraduate nursing education in South Africa. Nurse Educ Today 2011;31:253-258. https://doi.org/10.1016/j.nedt.2010.11.007 
19. Motseke M. Reason for the slow completion of Master's and doctoral degrees by adult learners in a South African township. Austr J Adult Learn 2016;56(3):424-441.

. Maasdorp C, Holtzhausen SM. Bridging the gap towards postgraduate studies at the Central University of Technology, Free State. Interdiscipl J 2011;10(1):38-51.

21. Jooste K, Jasper M. A South African perspective: Current position and challenges in health care service management and education in nursing. J Nurs Manag 2012;20(1):56-64. https://doi.org/10.1111/j.13652834.2011.01342.x

22. Rosseter R. Nursing faculty shortage. 2012. www.aacn.nche.edu/media-relations/fact/nursing-faculty-shortage (accessed 17 May 2020).

23. Coetzee SK, Klopper HC, Kim MJ. The quality of doctoral nursing education in South Africa. Curationis 2015;38(1):1-9. https://doi.org/10.4102\%2Fcurationis.v38i1.1441

24. Dlungwane T, Voce A, Searle R, Wassermann J. Understanding study student early departure from Master's of public health programme in South Africa. Afr J Health Professions Educ 2017;9(3):111-115. https://do org/10.7196/AJHPE.2017.v9i3.793

25. Dell S. South Africa: Decline in PhD numbers a major problem. University World. 2010. http://www.asocsa. org/news_articles/SharonDell_UniversityWorldNews_\%20SOUTH\%20AFRICA-Decline-in-PhD-numbers-amajor-problem-22August2010.pdf (accessed 30 July 2020).

26. Muraraneza C, Mtshali F, Mthembu SZ. Research supervision: Perceptions of postgraduate nursing students at higher education institution in KwaZulu-Natal, South Africa. Afr J Health Professions Educ 2016;8(2):135-139. https://doi.org/10.7196/AJHPE.2016.v8i2.294

27. Comley-White N, Potterton J. The perceived barriers and facilitators in completion a Master's degree in physiotherapy. S Afr J Physiother 2017;74(1):1-5. https://doi.org/10.4102/sajp.v74i1.445

28. Walliman N. Research Methods: The Basics. 1st ed. New York: Routledge, 2011

9. Okoduwa SI, Abe JO, Samuel BI, et al. Attitudes, perceptions, and barriers to research and publishing amon research and teaching staff in a Nigerian Research Institute. Front Res Metrics Analyt 2018;25(3):26

30. Botma Y, Roets L. Ways to improve research outputs of nurse academics in Sub-Saharan Africa. J New Gen Sci 2013;11(1):31-41.

31. McCulloch A, Thomas L. Widening participation to doctoral education and research degrees: A research agenda for an emerging policy issue. High Educ Res Develop 2013;32(2):214-227. https://doi.org/10.1080/07294360.2 012.662630

32. Grobler H. A supervision tool to guide postgraduate students during research supervision. Res Soc Work Pract 2015;27(2):246-263. https://doi.org/10.25159/2415-5829/366
33. Roets L, Botma Y. Cyclic efforts to improve completion rates of Master's degree student in nursing. Curationis 2012;35(1):1-7. https://doi.org/10.4102/curationis.v35i1.11

34. Chikte UME, Chabilall JA. Exploration of supervisor and student experiences during Master's studies in healt science. S Afr J Higher Educ 2016;30(1):57-79. https://doi.org/10.20853/30-1-559

35. Severinsson E. Research supervision: Supervision style, research-related tasks, importance and quality - part 1 J Nurs Manage 2012;20:215-223.

36. Mafora P, Lessing A. The voice of external examiner in masters dissertations. S Afr J High Educ 2014;28(4):1295-1314

37. National Research Foundation. List of NRF rated researchers. 2015. http://www.nrf.ac.za/sites/default/files/ documents/List $\% 20$ of $\% 20$ NRF\%20researchers\%20with\%20a\%20valid\%20rating_28\%20Feb\%202015 Web.pd (accessed 11 March 2019).

38. Roets L, Botha D, van Vuuren L. The research supervisors expertise or postgraduate student preparedness Which is the real concern. Afr J Nurs Midwifery 2017;19(2):1-10. https://doi.org/10.25159/2520-5293/3740

39. Couper I, Mash B. African primary care research: Writing a research report. Afr I Prim Health Care Fam Med 2014;6(1):1-5. https://doi.org/10.4102\%2Fphcfm.v6i1.639

40. Ismail A, Abiddin NZ, Hassan A. Improving the development of postgraduates' research and superud 2011;4(1):78-89.

41. Rout C, Aldous C. How to write a research protocol. S Afr J Anaesth Analg 2016;22(4):101-107.

42. Hofstee E. Constructing a good dissertation. A practical guide to finishing a Master's, MBA or PhD on schedule 2018. www.exactica.co.za (accessed 31 August 2020).

43. Chukwuere JE, Chukwuere PC. Guide for postgraduate student research and publication: A step-by-step approach. In: Dervin F, ed. Handbook of Research on Connecting Research Methods for Information Science Research. Helsinki: Timely Knowledge, 2020:529-550.

44. Dreifuerst KT, McNelis AM, Weaver MT, Broome ME, Draucker CB, Fedko AS. Exploring the pursuit of doctoral education by nurses seeking or intending to stay in faculty roles. J Prof Nurs 2016;32(3):202-212. https://doi. org/10.1016/.profnurs.2016.01.014

45. Naidoo JR, Mthembu S. An exploration of the experiences and practices of nurse academics regarding postgraduate research supervision at a South African university. Afr J Health Professions Educ 2015;7(2):216-219. hosttps://doi.org/10.7196/AJHPE.443

Accepted 13 July 2020. 